\title{
Urgences
}

\section{L'écoute obligée}

\section{Renée-Berthe Drapeau, N'entendre qu'un son, Montréal,} l'Hexagone, 1988, 108 p.

\section{Hughes Corriveau}

Numéro 23, avril 1989

Lisière du livre

URI : https://id.erudit.org/iderudit/025524ar

DOI : https://doi.org/10.7202/025524ar

Aller au sommaire du numéro

Éditeur(s)

Urgences

ISSN

0226-9554 (imprimé)

1927-3924 (numérique)

Découvrir la revue

Citer ce compte rendu

Corriveau, H. (1989). Compte rendu de [L'écoute obligée / Renée-Berthe Drapeau, N'entendre qu'un son, Montréal, l'Hexagone, 1988, 108 p.l Urgences,

(23), 141-142. https://doi.org/10.7202/025524ar d'utilisation que vous pouvez consulter en ligne.

https://apropos.erudit.org/fr/usagers/politique-dutilisation/ 


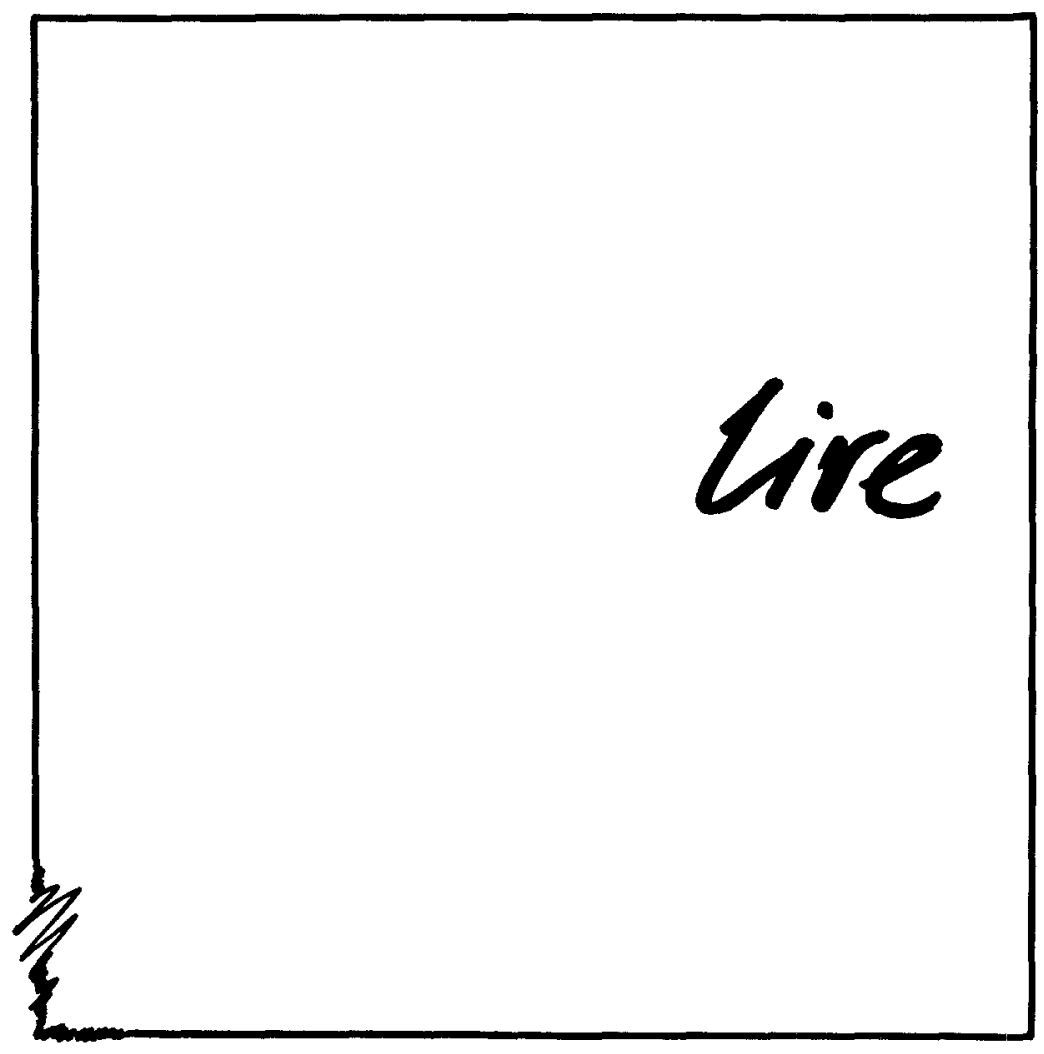




\section{L'écoute obligée Renée-Berthe Drapeau, N'entendre qu'un son, coll. «Fictions», Montréal, l'Hexagone, 1988, 108 p.}

N'y aurait-il ici que le projet d'entendre une écriture que nous serions conviés à un grand événement, mais il y a płus puisqu'il s'agit d'une écriture qui se construit, et d'une façon remarquable. Renée-Berthe Drapeau nous donne un premier roman d'une rare justesse de ton, un roman qui la désigne déjà comme une auteure à suivre. Car elle n'a pas pris le chemin de la facilité en produisant ce texte, bien au contraire. On se perd un peu dans les dédales de cette histoire, on se questionne aussi, ce qui n'est pas de tout repos, sans compter qu'on s'étonne, qu'on y prend plaisir, qu'on relit un passage, qu'on revient, repart, recommence; pour tout dire, on s'y plaît comme on devrait se plaire dans tout livre digne de ce nom, mais c'est une chose si rare, si peu commune. N'entendre qu'un son nous convie à une aventure du rêve dont l'écriture elle-même prend la charge, dont le style lui-même tend à répondre. Mais un rêve particulier puisqu'il est éveillé, qu'il questionne la réalité immédiate, tout comme le lieu de l'écriture, le monde de l'enfance, l'environnement sonore, les petits délires quotidiens, toute l'effervescence d'une conscience active, vivante, inquiète.

II pourrait sembler présomptueux de vouloir résumer ce roman car il est fait d'une suite assez floue d'impressions inattendues, de scènes venues à la fois de la réalité comme du désir, d'une structure baroque qui donne à l'opposition un rôle fonctionnel. Et c'est tant mieux, car ce qui nous reste de cette histoire tient plus à une mosaïque dont les éléments s'avèrent toujours intéressants dans la mesure où Renée-Berthe Drapeau a su leur garder leur pleine charge d'émotion. Mais on pourrait tout de même tenter de cerner ce qui se joue ici. Une jeune femme veut écrire un roman et pour ce faire s'attarde à écouter la vie, son battement, sa surprenante diversité. À travers ce travail d'écoute, elle parle de son frère avec qui elle a une relation privilégiée, ne serait-ce que pour critiquer ses manies, son mode de vie. Se tracent alors les signes d'un quotidien curieux au centre duquel une femme regarde aussi intensément qu'elle écoute. Elle ponctue son existence d'arrêts attentifs pour laisser le monde lui entrer dans l'oreille, de moments plus ou moins longs à la fenêtre où elle regarde les passants, de stations plus longues encore à sa table de travail où elle laisse venir les échos de Duras, les histoires imaginaires d'amants, de bateaux, de noyé, d'étrangers passionnés et d'amours inquiètes. Bref un univers multiple dont il s'agit de saisir au passage les signes pour ne pas s'y perdre, pour prendre en main le plaisir d'une lecture qui ne saurait être qu'active, dynamique. Mais encore, faut-it à cette héroïne des musiques étranges, celles de Laurie Anderson, le Gesang der Jünglinge de Karlheinz Stockhausen, Pulau Dewata de Claude Vivier, Ishuma de Micheline Coulombe Saint-Marcoux, Fleuves de Gilles Tremblay, toutes ces musiques qui vont ponctuer le roman de leurs échos comme s'il fallait à ce lieu une certaine harmonie cassée, un miroir musical brisé comme l'est la structure même de ce livre qui raconte par coups mesurés, par crises de tensions. Et à travers tout cela se dessine la véritable histoire de ce livre, soit la rencontre de la narratrice avec sa mère, moment d'une intense mise en scène puisque c'est vers lui que tend toute la fiction, qui cherche à rejoindre, sur les rebords refoulés de l'enfance, les difficultés d'admettre certaines évidences du sentiment. À force de suivre les méandres de cette écriture, on en vient à admirer l'efficacité de l'auteure à concilier des scènes narratives d'une très grande simplicité dans une structure romanesque plus érudite, fort savante même qui va chercher l'écoute du lecteur que nous sommes, de telle sorte que nous soyons toujours à l'affût de cette musique du style: 
Vous pourriez écrire ce roman dans la langue anglaise, assise ici même, la tête sous la lampe drue chauffant le front.

Première phrase du roman, première surprise, car l'audace de vouloir écrire un autre roman au "vous», après tant d'autres, ne va pas de soi. Mais la magie opère, car ce «vous" est le mot qui capte ici le lecteur ou le fait fuir, ce petit pronom qui intrigue dans son exigence absolue:

Cette nuit, vous avez encore rêvé de dents qui tombent. Vous aviez de l'or dans la bouche et vous l'avaliez sans le faire exprès, en déjeunant. Vous cherchiez à arracher le morceau dur, mais celui-ci filait droit dans votre gorge. Vous passiez votre langue sur la partie dénudée de vos gencives, inquiète. Vous songiez que tout le monde vous regardait. Vous mâchiez avec difficulté. Un homme vêtu de noir vous lorgnait à travers une espèce d'instrument que vous situiez entre le téléscope et les verres fumés. Cet appareil émettait un bruit continu, un léger ronronnement. Un rappel précis et lent de vieux film, la fraise à percer les dents. Cela cachait quelque chose, des milliers d'insectes. Vous murmuriez des secrets, la bouche pleine d'eau. Que cherchiez-vous à déverser entre vos lèvres? Vous avez raison, l'on entend que ça. Pour écrire, les dents manquent. Vous vous êtes surprise, assise en train d'écrire. Le roman achevait. De lui-même, une locomotive suivie de ses wagons.

Voilà, ce long extrait nous donne tout entier le roman. À quoi servirait-il de raconter la fin, la suite des événements qui vont faire de ce texte une véritable "histoire»? L'histoire entière de ce livre tient dans l'aventure d'une écriture qui parvient à son propre son, à se faire entendre. Je crois que cette auteure a su tracer, par ce coup d'envoi, par ce premier cri, la voie à sa propre écriture, a su inscrire un premier texte d'une très rare intensité, magnifiquement écrit (ce qui n'est pas si fréquent) et que tous ceux et celles qui aiment autre chose que de l'écriture de consommation devraient s'empresser de lire avec le plaisir que seuls les beaux textes savent procurer.

Hugues Corriveau 